\title{
Contradições entre desenvolvimento, trabalho e espaço em tempos de crise: o caso do estado do Rio de Janeiro
}

\author{
Contradictions among development, labor and space \\ in periods of crisis: the case of Rio de Janeiro
}

Hipólita Siqueira de Oliveira*

\begin{abstract}
Resumo
Em tempos de crise é comum se afirmar que os limites e as contradições dos modelos econômicos e políticos se revelam. As crises recentes deságuam em pressões para redução de gastos públicos, aumento do desemprego e propostas de redução de direitos trabalhistas e sociais. Argumenta-se, neste artigo, que as características e as contradições mais gerais do modelo de desenvolvimento nacional e de sua crise podem ser melhor observadas em suas dimensões espaciais e do trabalho. Desse modo, o objetivo é examinar as transformações em tais dimensões no Brasil e no estado do Rio de Janeiro, entre 2003 e 2016, tendo em vista haver grande articulação entre o ciclo nacional e o dessa Unidade da Federação. $A$ análise utiliza informações estatísticas do IBGE, sobretudo a Pesquisa Nacional por Amostra de Domicílio/Pnad.
\end{abstract}

Palavras-chave: desenvolvimento; trabalho; espaço; crise; petróleo.

\begin{abstract}
During periods of crisis, it is common to state that the limits and contradictions of economic and political models are revealed. Recent crises have triggered pressures to reduce public spending; moreover, they have increased unemployment and brought proposals to reduce labor and social rights. In this article, we argue that the general characteristics and contradictions of the national development model and its crisis can be best observed in their spatial and labor dimensions. Thus, the objective is to examine transformations in these dimensions in Brazil and in the state of Rio de Janeiro between 2003 and 2016, given that the national cycle and the cycle of this state are largely articulated.
\end{abstract}

Keywords: development, labor, space, crisis, oil industry. 


\section{Introdução}

Nas últimas décadas, as interpretações sobre o modelo econômico brasileiro tiveram como marco o esgotamento, nos anos 1980, do chamado nacional-desenvolvimentismo (19301980), baseado no modelo de industrialização por substituição de importações. Mais do que uma "década perdida", essa poderia ser vista como uma fase de transição para um novo regime caracterizado pela adoção de medidas neoliberais nos anos 1990. No entanto, no período pós-2003, a retomada do protagonismo do Estado no que se refere à realização de investimentos e gastos sociais, com forte papel de estatais e de bancos públicos, indicaria a delimitação de uma fase contraditória em relação ao que vinha se configurando nos anos 1990.

Após um curto período de crescimento econômico (2004-2009), em que se articularam melhorias dos preços internacionais de commodities e políticas de fomento ao mercado interno, o momento histórico recente tem sido analiticamente importante para se interpretarem as características e os limites do modelo brasileiro. De certa forma, a sobreposição das crises externa e interna reflete um movimento mais geral que ocorre na América Latina, especialmente no que se refere àqueles países que adotaram políticas ditas "pós-neoliberais".

Além das várias frentes de contestação social, iniciadas em 2013 e que culminaram com o impeachment da presidenta Dilma Roussef em 2016, também é revelador do momento crítico o decreto de estado de calamidade pública do governo estadual do Rio de Janeiro há poucos dias do início dos Jogos Olímpicos de 2016 na capital fluminense. A crise recente deságua sobretudo em pressões para a redução de gastos públicos e sobre 0 trabalho, com o aumento do desemprego e de propostas de redução de direitos trabalhistas e sociais.

0 principal argumento deste artigo é que as características e as contradições mais gerais do modelo de desenvolvimento em âmbito nacional podem ser melhor observadas em suas dimensões espaciais e do trabalho, bem como em suas articulações. Nesse sentido, no período denominado "lulismo" por Singer (2012), destaca-se a manutenção de uma política macroeconômica comprometida com os interesses financeiros em contraste com uma certa redistribuição de renda, caracterizada sobretudo pela política de valorização continuada do salário mínimo e de políticas sociais (programas de transferência direta de renda, benefício de prestação continuada, habitacional e outros). No entanto, tais processos ocorreram sem alterações estruturais significativas (produtivas, fiscais, ocupacionais, sociais, espaciais, etc.). Esses movimentos podem ser identificados na análise econômica do estado do Rio de Janeiro, caracterizada por intensificação da especialização produtiva em commodities (petróleo), concentradas espacialmente e da dinâmica cíclica (econômica e do mercado de trabalho). Além disso, do ponto de vista do mercado de trabalho, a vulnerabilidade a flutuações do ciclo de commodities contrasta com relativa meIhora observada pela ampliação dos vínculos empregatícios formalizados e pela redução do emprego por conta própria.

Entretanto, não se pretende, nos limites de um artigo, esgotar toda a problemática do modelo econômico e as especificidades das mudanças nessas dimensões, mas relacioná-las, entendendo-as como importantes 
para se pensar os processos de desenvolvimento e suas crises. Do mesmo modo, entende-se que as contradições são próprias do sistema capitalista, em que o crescimento econômico é acompanhado por intensificação da exploração do trabalho, concentração espacial e produção de múltiplas desigualdades. Busca-se analisar as particularidades de um processo de desenvolvimento econômico em sua multiescalaridade.

Tendo em vista tais considerações, o objetivo deste artigo é examinar as transformações nas dinâmicas econômica, espacial e do trabalho no Brasil e no estado do Rio de Janeiro (ERJ), ao longo do período de 2003 a 2016. Vários estudos demonstram que há grande articulação entre a dinâmica do ciclo nacional e dessa unidade da federação. Desse modo, configura-se em espaço privilegiado para observar tendências como especialização regressiva e vulnerabilidade da dinâmica econômica e dos mercados de trabalho, submetidos a drásticas flutuações nos preços das commodities no mercado internacional.

0 artigo está dividido em duas partes, além das seções introdutória e das considerações finais. Na primeira parte, busca-se compreender o ciclo de mudanças e permanências do desenvolvimento brasileiro nas duas primeiras décadas do século XXI, em termos das dimensões espaciais e do "mundo do trabalho". Além de informações estatísticas, são examinadas várias interpretações sobre características, limites e contradições do modelo econômico e político brasileiro. Na segunda parte, algumas questões mais gerais do modelo brasileiro serão analisadas tendo como base a dinâmica econômica espacial e do trabalho e da crise atual no estado do Rio de Janeiro.

\section{0 modelo brasileiro nos anos 2000: nova rodada desenvolvimentista ou neoliberal?}

Segundo várias interpretações sobre o período pós-2003, a retomada do protagonismo do Estado no que se refere à realização de investimentos e gastos sociais, com forte papel de estatais e de bancos públicos, indicaria a delimitação de uma fase contraditória em relação ao que vinha se configurando nos anos 1990. Nesse período, as taxas de crescimento econômico nacional foram positivas e superiores às do período 1980-2002 (cerca de 2\% a.a.). Entre 2004-2008, a economia nacional cresceu a uma taxa média anual de cerca de $5 \%$, apresentando em 2009, como reflexo da crise externa, um decrescimento de $0,1 \%{ }^{1}$

0 crescimento econômico foi liderado, em grande parte, pelo aumento das exportações, dinamizadas pela abundância da liquidez internacional e pelo boom de preços das commodities agrícolas e minerais entre 2003-2008 (soja, minério de ferro, petróleo, etc.), com destaque para o "efeito-China". Ao mesmo tempo, cabe ressaltar a importância da eleição de um governo advindo da classe trabalhadora e a ascensão de uma nova correlação de forças no plano político nacional, associando esse contexto internacional favorável, de melhoria nos termos de troca, a políticas de fortalecimento do mercado interno e aumento do consumo de massas, tais como valorização contínua do salário mínimo, expansão do emprego, ampliação do crédito ao consumo e habitacional e políticas de transferência de renda, dentre outras. 
A provisão de crédito teve como agentes centrais os bancos públicos (BB, BNDES e CEF). Além disso, também foi importante o papel da Petrobras via aumento de sua produção e de programas de investimentos, com destaque para a descoberta do pré-sal, e a articulação de seus investimentos com outros setores, especialmente a valorização da indústria naval nacional com a implementação do Programa de Mobilização da Indústria Nacional de Petróleo e Gás Natural/Prominp. Completa esse quadro a retomada de programas do Governo Federal em infraestrutura econômica e urbana (Programa de Aceleração do Crescimento), com fortes impactos na dinâmica regional e urbana do País.

No período após a eclosão da crise de 2008, a adoção de medidas anticíclicas pelo Governo Federal, com o objetivo de sustentar a renda e o emprego (via expansão do crédito, controle de preços administrados, desoneração e subsídios às empresas), mantive o dinamismo no mercado de trabalho, garantindo a valorização do salário mínimo e os programas sociais. Da mesma forma, foram mantidos investimentos em infraestrutura previstos no PAC-2, os investimentos da Petrobras e foi lançado, em 2009, o Programa Minha Casa Minha Vida (PMCMV), ampliando o mercado habitacional para famílias com renda até 10 salários mínimos.

Contudo, tais medidas não garantiram o mesmo nível de crescimento do período 20042008. Em 2010, a taxa de crescimento foi significativa, de 7,5\%, porém, não se sustentando e desacelerando nos anos seguintes: 3,9\% em 2011; 1,9\% em 2012; 3\% em 2013; 0,1\% em 2014. A partir do final de 2014, a conjuntura de crise externa articula-se à crise interna com aumento da inflação e do déficit público e desvalorização cambial. Em 2015, o decrescimento de 3,8\%, resultou em grande medida da opção do governo Dilma Roussef por forte ajuste fiscal em um contexto de desaceleração do crescimento verificado nos anos anteriores.

Nos anos 2000, a taxa global de investimento permaneceu praticamente imutável, indicando os limites da estratégia assentada primordialmente no crescimento do consumo induzido por exportações e reaquecimento do mercado interno, relegando o investimento a uma posição secundária. A participação relativa da Formação Bruta de Capital Fixo (FBCF) no PIB manteve-se próxima à dos anos 1990 , entre $15 \%$ e $17 \% .^{2}$ Porém, coincidindo com os programas do Governo Federal (PAC e PMCMV), houve ligeiro aumento dessa taxa a partir de 2008 , subindo para cerca de $20 \%$ entre 2010-2014, voltando a cair para 18\% em 2015. Em ambiente de manutenção de taxas de juros elevadas, recorrente apreciação cambial e a não implementação de um planejamento nacional em áreas estratégicas (industrial, ciência e tecnologia), não houve um vigoroso ciclo de investimentos na economia brasileira.

Um balanço geral feito pelo Dieese (2016) destaca que, entre 2004 e 2014, houve uma melhora geral dos indicadores do mercado de trabalho, com redução da taxa de desemprego, aumento significativo de vínculos empregatícios formais (com carteira assinada e, em menor medida, emprego público) e aumento do rendimento médio real do trabalho, acompanhado de melhora em seu perfil distributivo. Segundo esse balanço, a deterioração dos indicadores do mercado de trabalho ocorre, de modo intenso e rápido, a partir de 2015, com aumento das taxas de desemprego, 
aumento dos vínculos informais e queda do rendimento médio real do trabalho e da massa de rendimentos. Com base nos dados da Pnad Contínua do IBGE, ${ }^{3}$ que apresenta informações conjunturais do mercado de trabalho, a taxa de desocupação cresceu, a partir do último trimestre de $2014,6,5 \%$, atingindo $10,9 \%$ no primeiro trimestre de 2016.

Com a expansão do mercado interno, houve redução da pobreza e das desigualdades de renda, sendo incorporadas cerca de 16 milhões de famílias ao consumo moderno. Além das políticas previdenciárias e de transferência de renda, foram centrais para esse movimento a expansão do crédito ao consumo e a política de elevação contínua do salário mínimo. Somaram-se, a essas ações, programas de estímulo à agricultura familiar (Pronaf), eletrificação rural (Luz para Todos), de desenvolvimento territorial (Territórios da Cidadania), de interiorização do ensino superior (institutos federais e universidades federais) e outros cujos impactos sociais, políticos e espaciais merecem avaliação mais aprofundada.

Vários estudos vêm buscando interpretar características, limites e contradições do modelo econômico e político brasileiro, já sob a perspectiva dos impactos da crise internacional de 2008 e de seus desdobramentos. Dentre eles, Oliveira, Rizek e Braga (2010), Carneiro (2012b), Singer (2012), Nobre (2013), Bresser-Pereira (2013), Gonçalves (2013), Fonseca et al., (2013) e Paulani (2013), pautando os debates pelas interpretações elaboradas com base na designação de conceitos como "hegemonia às avessas"; "neodesenvolvimentismo" e "lulismo".

Sobre o modelo econômico, dentre as principais contradições, estão a (re)afirmação do País como plataforma de exploração de recursos naturais, em um contexto de políticas voltadas para o mercado interno. Para Paulani (2013), sob elevadas taxas de juros e apreciação cambial, haveria a configuração, desde os anos 1990, de um regime econômico baseado na inserção internacional do País como plataforma de valorização financeira.

Os efeitos desse modelo sobre o desadensamento das cadeias produtivas (desindustrialização ${ }^{4}$ ) já se apresentavam nos anos 1990, tendo em vista o ajuste produtivo realizado em contexto de elevadas taxas de juro e valorização cambial, mantido nos anos 2000 (Carneiro, 2012a). Ao mesmo tempo, a reprimarização da estrutura produtiva nacional, reforçada pelo ciclo de preços das commodities entre 20032008 , do ponto de vista espacial, acentua tendências históricas do modelo pré-1930, de formação de enclaves extrativistas no interior das regiões e de estados brasileiros.

Em termos políticos, a análise de Singer (2012) identifica um fenômeno complexo e contraditório que denomina lulismo, fenômeno marcado por uma opção intermediária ao neoliberalismo e ao reformismo forte, característico do programa do PT até as vésperas da campanha eleitoral de 2002. Com isso, particularmente no segundo mandato de Lula, orientou-se o Estado para a implementação de políticas favoráveis aos mais pobres, contudo, sem confrontar a ordem. Singer avalia que, ao promover um reformismo fraco, desestimulando conflitos, estendeu-se no tempo a redução das desigualdades sociais, sem mobilização e organização desde baixo.

Outras análises, como as de Pinto (2010), feitas sob a perspectiva da economia política e do bloco do poder, tornam esse quadro mais 
complexo. Pinto considera tanto determinações externas, advindas da configuração de um novo eixo sino-americano na constituição de uma hegemonia internacional, como as opções de políticas econômicas internas e o desempenho dos grupos econômicos que atuam no País. Com isso, demonstra a manutenção, durante os dois governos de Lula, da dominação da fração bancário-financeira, por conta da continuidade da política macroeconômica do final dos anos 1990. Por outro lado, observou um aumento do poder do setor do agronegócio exportador e da indústria intensiva em recursos naturais, tendo em vista o ciclo expansivo do preço das commodities puxado pela demanda externa chinesa.

Diante das crises econômica e política interna do País, acentuadas em 2016, também caberia destacar a manutenção das articulações políticas históricas entre Estado e os grupos empresariais do setor da construção civil. Os impactos da operação Lava Jato da Polícia Federal na Petrobras, associados à redução da demanda externa e à queda brusca dos preços internacionais do barril do petróleo, implicaram a revisão do plano de negócios da estatal, com efeitos negativos na economia nacional como um todo e em economias estaduais do Nordeste (Pernambuco, Rio Grande do Norte, Bahia e Ceará) e Sudeste (Rio de Janeiro e Espírito Santo).

No que se refere às questões sociais e do "mundo do trabalho", alguns estudos entenderam a incorporação de milhões de brasileiros ao consumo como sendo representativa de um modelo de crescimento com equidade, até então, inédito na história brasileira. Em Neri (2011), esse movimento foi compreendido como de ascensão de uma "nova classe média", corroborado pelos discursos do Governo Federal. Outros autores, porém, consideraram que chamar essa camada de ingressantes no padrão de consumo de "nova classe média" seria prematuro ou indevido (Pochmann, 2012 e Bartelt, 2013).

De acordo com Pochmann (2012), a ampla geração de postos de trabalho ocorreu na base da pirâmide social. Isso se refletiu em aumento da renda per capita e na melhoria da distribuição da renda pessoal do trabalho, com melhorias nos indicadores gerais do mercado de trabalho (redução do desemprego e formalização dos vínculos) e queda da pobreza absoluta. Foram criadas principalmente ocupações no setor de serviços, com rendimento médio mensal de até 1,5 salários mínimos. $\mathrm{A}$ expansão do mercado de trabalho, aliada às políticas de valorização real do salário mínimo e de transferência direta de renda, fortaleceu as classes populares assentadas no trabalho que, por sua vez, com a elevação de seus rendimentos, ampliaram seu padrão de consumo. Portanto, é inadequado interpretar a expansão do período como sendo de criação e fortalecimento de uma "nova classe média". Para esse autor, tal compreensão conceitual expressaria uma disputa sobre a concepção de políticas públicas, reorientando-as para a mercantilização de serviços, tais como planos de saúde, escolas particulares, planos de previdência privada, etc.

Ainda na perspectiva das classes sociais, estudos sociológicos, como os de Braga (2012), buscaram entender esses movimentos a partir da emergência do "proletariado precarizado", desde a década de 1990. Tal segmento é constituído por trabalhadores com inserção precária e flutuante no mercado de 
trabalho, tais como jovens no primeiro emprego, trabalhadores sub-remunerados em condições degradantes, sob ameaça constante de exclusão social. Segundo esse autor, apesar do aumento dos vínculos formais, ainda é grande a presença do tipo de emprego precarizado no mercado de trabalho brasileiro. Mesmo com o aumento da formalização e de melhorias salariais, permanecem tendências históricas das relações de trabalho (alta rotatividade) e de outras que se delinearam nos anos 1990 (flexibilização e precarização).

Especificamente sobre as questões da ação sindical, Krein, Dias e Colombi (2015) observaram movimentos contraditórios em relação à ascensão de um governo oriundo dos movimentos sindicais e os limites à ação coletiva em contexto geral de internacionalização econômica, flexibilização das relações de trabalho e fragilização dos sindicatos desde os anos 1990. 0 quadro geral de terceirização e fragmentação setorial do mercado de trabalho e seus desafios para a ação coletiva permaneceram nos anos 2000, embora tenham ocorrido melhoras nos indicadores do mercado de trabalho e de seus efeitos positivos do ponto de vista da negociação coletiva. Esses autores destacam várias fases de relacionamento entre as centrais sindicais e o Governo Federal, aproximando-se mais no segundo mandato de Lula e distanciando-se durante os governos Dilma. Ao longo do período, houve várias divisões no sindicalismo e foram criadas novas centrais sindicais, e, a partir de 2013, houve um aumento do número de greves, inclusive no setor do funcionalismo público e em obras do PAC em todo o País.

Essas transformações e contradições mais gerais do modelo em âmbito nacional podem ser melhor observadas em suas dimensões espaciais (regionais e urbanas).

0 padrão contemporâneo marcado por perdas de quantidade e qualidade de importantes elos das cadeias produtivas (não apenas em setores de maior intensidade tecnológica, mas também em setores intensivos em emprego) contrasta com aquele do período nacional-desenvolvimentista em que o crescimento acompanhava significativa diversificação da estrutura produtiva, sendo marcado pelo processo de integração do mercado nacional.

Cabe lembrar que o nacional-desenvolvimentismo, sobretudo durante o período militar, também foi marcado pela continuidade da "marcha para o oeste" (e norte) do País, caracterizada pela apropriação privada do território e pela abertura de novas fronteiras agrícolas e minerais, gerando conflitos pela posse da terra e fluxos migratórios que impactaram na formação de núcleos urbanos adensados fora da faixa litorânea. Por outro lado, os grandes projetos de investimento do II PND na década de 1970 foram determinantes na criação de novas regiões fora do núcleo central de acumulação do País e dentro das macrorregiões em que se instalaram (Piquet, 1993). Em geral, configurando-se em enclaves extrativistas exportadores, com poucas interações com a região em que se localizaram.

No período pós-2003, foram importantes as tendências positivas de maior dinamização das regiões de menor PIB via programas sociais, estímulo ao mercado interno e investimentos em infraestrutura. Pelos dados do IBCR (Índice de Atividade Econômica Regional), elaborados pelo Banco Central do Brasil, entre 2004-2011, observa-se que as regiões de maior crescimento econômico foram o Norte 
$(5,2 \%)$ e Nordeste (5\%). Sudeste e Centro-Oeste cresceram a taxas semelhantes, 4,6\% e 4,2\%, respectivamente. 0 Sul apresentou a menor taxa de crescimento, 3,8\%. Do mesmo modo, as regiões que tiveram maior crescimento de participação relativa nos desembolsos anuais do BNDES, entre 2003-2012, foram as regiões Norte (de 2,1\% para 8,6\%), Nordeste (de $9,3 \%$ para $13,5 \%$ ) e Centro-Oeste (de $8,4 \%$ para 12,9\%). Pelas informações das Contas Regionais do IBGE, tal dinamismo não se refletiu em fortes mudanças na distribuição regional do PIB. Entre 2002-2010, houve pequeno aumento da participação relativa do Norte (de 4,7\% para 5,3\%) e do Centro-Oeste (de 8,8\% para $9,3 \%$ ). No caso do Nordeste, sua participação relativa manteve-se em $13 \%$.

Do ponto de vista regional, foram relevantes os impactos dos estímulos ao mercado interno e dos programas sociais sobre a Região Nordeste, por conta do grande percentual relativo de pobreza e de população com rendimentos na faixa de 1 salário mínimo (Araujo, 2013). Entretanto, em termos gerais, boa parte do dinamismo regional, sobretudo do Norte (minérios) e Centro-Oeste (grãos), esteve baseada em setores exportadores de commodities (intensivos em escala, não difusores de progresso tecnológico e de elevada relação capital/ trabalho). Principalmente no caso do Norte, são regiões cuja dinâmica econômica, social, territorial e ambiental é significativamente afetada pelos grandes projetos de investimento de infraestrutura, em sua maioria, associados ao fortalecimento de enclaves extrativistas. Por outro lado, mesmo no interior de outras regiões de maior densidade produtiva, como o Sudeste, também é possível observar claras tendências de especialização extrativista de algumas UFs, tal como demonstra o caso do Rio de Janeiro que será analisado na seção seguinte. Em outra perspectiva escalar da dinâmica regional, os projetos de investimento, especialmente de extração do petróleo e de infraestrutura para exportação de commodities (corredores logísticos envolvendo rodovias, ferrovias e portos), indicam uma retomada da tendência histórica de concentração de atividades econômicas no litoral brasileiro. Também dessa perspectiva há grande destaque para a extração de petróleo e de projetos de infraestrutura logística no litoral fluminense.

Contudo, a permanência de percentuais relativos do PIB historicamente menores das regiões Norte $(5,3 \%)$ e Nordeste $(13,5 \%)$ em comparação aos do Sudeste $(55,4 \%)$ indica a persistência das desigualdades macrorregionais, projetadas em uma divisão inter-regional do trabalho sem alterações significativas no período analisado. Em tempos de crise econômica e de redução dos gastos e investimentos públicos, provavelmente se acentuarão as tendências de reconcentração na região e na UF de maior peso econômico e centro da acumulação de capital do País, Sudeste e São Paulo.

$\mathrm{Na}$ escala intraurbana, algumas contradições do modelo expressaram-se nas políticas de crédito ao consumo e de subsídio às empresas (especialmente à indústria automobilística), bem como no PMCMV. Embora tenham sido políticas anticíclicas favoráveis ao fortalecimento do mercado interno, resultando na manutenção de empregos e da massa salarial, causaram pressões negativas na mobilidade urbana e na valorização dos preços dos imóveis. No caso do PMCMV, embora tenha sido importante por atender a uma camada da população de baixa renda e vir de encontro aos 
anseios dos movimentos populares por moradia, Cardoso e Aragão (2013, p. 44) sintetizam críticas significativas dos estudos que avaliaram o programa:

(i) a falta de articulação do programa com a política urbana; (ii) a ausência de instrumentos para enfrentar a questão fundiária; (iii) os problemas de localização dos novos empreendimentos; (iv) excessivo privilégio concedido ao setor privado; (v) a grande escala dos empreendimentos; (vi) a baixa qualidade arquitetônica e construtiva dos empreendimentos; (vii) a descontinuidade do programa em relação ao SNHIS e a perda do controle social sobre a sua implementação. A esses pontos, já destacados por várias análises, acrescentamos ainda (viii) as desigualdades na distribuição dos recursos como fruto do modelo institucional adotado. (Ibid., p. 40)

Com relação à ausência de articulação entre o programa, a política fundiária e a política urbana, esses autores observaram que houve uma pressão de demanda por terra com efeitos altistas sobre os preços imobiliários. Sendo assim, nos empreendimentos do programa, prevaleceu a tendência de busca de terrenos mais baratos e distantes das centralidades urbanas e com infraestrutura precária. Com isso, estendendo a amplitude da periferização histórica das moradias para as classes de baixa renda no espaço urbano.

Os resultados do programa habitacional e dos programas de infraestrutura econômica (logística e energética) e social e urbana (saneamento e mobilidade incluídos no PAC-2), embora tenham sido significativos e de elevado montante, se comparados ao contexto de ausência desse tipo de investimento nos anos 1990, constituem agenda de pesquisa importante para o estudo de seus impactos espaciais (urbanos, rurais, regionais e ambientais). Assim como também devem ser analisados à luz das especificidades regionais e das cidades do Brasil, somando-se a isso casos de cidades receptoras de megaeventos internacionais (Copa, em 2014, e Olimpíadas, em 2016).

0 cenário atual de crise econômica e política, culminando com o impeachment da Presidenta Dilma Roussef em 2016, ao mesmo tempo que revela mais claramente os limites e as contradições do modelo econômico e político brasileiro é extremamente preocupante. Ainda não estão muito definidas as mudanças vindouras, mas propostas políticas, como as do projeto de lei 4567/2016, que retira da Petrobras a obrigatoriedade na exploração do petróleo, da proposta de emenda à Constituição 241/2016, que limita os gastos públicos por 20 anos, e do projeto de lei 4330/2004, que estende a terceirização do trabalho para as atividades-fim, e as propostas de reforma da previdência, indicam uma nova rodada neoliberal, com sérias implicações sobre as dimensões destacas acima.

No Estado do Rio de Janeiro, há grande articulação entre a dinâmica nacional e estadual, uma vez que se trata de uma economia altamente dependente da extração do petróleo e sob fortes pressões dos ciclos de preços internacionais dessa commodity, tal como será discutido na seção seguinte. 


\section{Economia, espaço e trabalho no estado do Rio de Janeiro}

No contexto da região Sudeste, núcleo central de comando da acumulação no País, a dinâmica econômica, espacial e do trabalho no Estado do Rio de Janeiro (ERJ) é reveladora das contradições do modelo brasileiro, tanto no passado como no presente. Tal como no título sugestivo do livro de Lessa (2000), O Rio de todos os Brasis.

Os estudos mais recentes sobre o ERJ têm buscado relativizar a visão preponderante baseada em um diagnóstico histórico de perdas dessa UF em relação a São Paulo no período nacional-desenvolvimentista, contrastada com um diagnóstico de ganhos no período "neodesenvolvimentista".

Autores como Silva (2012) relativizam a tese de que houve um "esvaziamento econômico" fluminense ao longo do período nacional-desenvolvimentista, destacando que essa UF foi fortemente influenciada pelas altas taxas de crescimento econômico do País e pela atuação do Estado, em termos tanto dos gastos públicos como dos investimentos das empresas estatais, por sua vez estratégicos para o processo de industrialização nacional. ${ }^{5}$ Ainda que, na escala intraestadual, esses investimentos tenham ocorrido de forma bastante seletiva, foram muito importantes em termos da configuração produtiva, urbana, regional e do mercado de trabalho fluminense.

A articulação entre as questões nacionais e fluminenses foi particularmente difícil na década de 1980. Com a crise fiscal e financeira do Estado, importantes segmentos industriais (siderurgia, mecânica, naval, têxtil e química), dependentes do mercado interno nacional e de estímulos diretos do Estado, foram negativamente impactados. Os setores de comércio, serviços e o funcionalismo público, fortemente concentrados na capital, sentiram os efeitos da crise nacional e da redução do investimento e dos gastos estatais. Na administração pública, no contexto hiperinflacionário da década, foi significativo o peso que o arrocho salarial do funcionalismo público teve sob a dinâmica econômica urbana da cidade do Rio e dos demais municípios metropolitanos (ibid.).

No período recente, contradições do desenvolvimento nacional se verificam no ERJ através dos desdobramentos espaciais e do trabalho determinados pela intensificação das atividades extrativistas, com aumento da produção e perspectivas de expansão das atividades de extração de petróleo e gás. A economia estadual também tem sido dinamizada por grandes projetos de investimentos (corredores logísticos e setores intensivos em recursos naturais e de elevada relação capital/trabalho), pela atração de megaeventos internacionais (Copa de 2014 e Jogos Olímpicos 2016, dentre outros) e pela realização de grandes projetos urbanos concentrados na cidade do Rio de Janeiro. De modo geral, são projetos caracterizados por intensas articulações entre estatais (com grande centralidade da Petrobras na reorganização territorial do espaço urbano e regional fluminense), bancos públicos, construtoras de capital nacional e empresas internacionais da área de petróleo e gás e siderurgia.

Importante destacar, nesse quadro, as tendências de internacionalização da economia fluminense que se manifesta com o aumento das exportações de petróleo e a atração de grandes transnacionais ${ }^{6}$ do setor 
de extração de petróleo e gás, intensificadas pela descoberta do pré-sal. ${ }^{7}$ Esse movimento insere o ERJ na disputa e pressões dos interesses geopolíticos e geoeconômicos atuais. Além disso, os projetos logísticos e portuários visam à transformação do território fluminense em plataforma logística de exportação de commodities. Também são evidentes as iniciativas de empreendedorismo urbano em torno dos projetos de transformação do Rio em cidade de megaeventos internacionais. Os impactos na cidade dos projetos de mobilidade urbana, construção de equipamentos para esporte, Porto Maravilha e das ações específicas para as favelas (Unidades de Polícia Pacificadora/ UPPs) são significativos, porém, com efeitos negativos relativos a remoções e especulação imobiliária (Castro et al., 2015).

Em síntese, analisando tais dinâmicas, os estudos sobre a realidade fluminense ${ }^{8}$ destacam mudanças e permanências em relação ao padrão histórico de desenvolvimento, indicando uma certa diversificação setorial e reorganização territorial. Além das transformações determinadas pela expansão das atividades de extração de petróleo e gás concentradas na região Norte Fluminense, algumas tendências novas são observadas na região Sul Fluminense, com a implantação do polo automobilístico, e no interior da Região Metropolitana do Rio de Janeiro (RMRJ): Arco Metropolitano, Polo Gás-Químico, Complexo Petroquímico do Rio de Janeiro (Comperj) e Porto de Sepetiba.

No entanto, desde os anos 1990, a dinâmica econômica estadual vem sendo fortemente influenciada pela indústria de extração de petróleo e gás e seu desempenho produtivo elevado. Como resultado de projetos do II PND (1974), a produção de petróleo começou a crescer intensivamente a partir de 1985, e o ERJ tornou-se responsável por cerca de $70 \%$ da produção nacional de petróleo e cerca de $40 \%$ da produção de gás natural em $2015^{9}$ (terra e mar). Em termos de crescimento econômiCo, o ERJ vem apresentando taxas que acompanham a trajetória dos ciclos da economia nacional. Na década de 2000, marcada pelo boom do preço internacional do barril do petróleo, o ERJ apresentou taxas de crescimento mais elevadas, seguindo o ciclo nacional, com queda após a eclosão da crise internacional em 2008. Segundo os dados das Contas Regionais do IBGE, a participação relativa fluminense no PIB nacional permaneceu em 11\%, entre 1995 e 2011. Isso se deveu claramente ao seu peso relativo na indústria extrativa nacional, cujo percentual mais que duplicou entre 1995 e 2011 (de 17\% para 40\%), enquanto, na indústria de transformação nacional, a contribuição do ERJ permaneceu em cerca de $6 \%$. A participação relativa da indústria extrativa no total do PIB fluminense saltou de 1,2\% em 1995 para 14,5\% em 2011.

De acordo com Pereira (2012), a reprimarização da pauta de exportações fluminense foi muito mais acentuada do que a nacional. Enquanto na fluminense o peso relativo dos produtos básicos aumentou de cerca de $40 \%$ para $70 \%$, na nacional o aumento foi de $26,3 \%$ para 44,6\%, entre 2001-2011. Ademais, em termos de composição da pauta de exportações, a fluminense é muito mais restrita, assentada no petróleo bruto que correspondeu a $70 \%$ do valor exportado pelo ERJ e $99,8 \%$ do total das exportações de produtos básicos, em 2011. Como resultado, a participação relativa do ERJ no total das exportações brasileiras aumentou de $3,3 \%$ para $11,5 \%$, entre $2000-2011$, passando 
a ocupar a terceira posição dentre as maiores UFs exportadoras do País.

Em termos fiscais, observa-se forte dependência dos governos estadual e dos municípios do Norte Fluminense em relação às rendas do petróleo (royalties e participações especiais), influenciando em seu desempenho de arrecadação, gastos e investimentos. Com a queda drástica dos preços internacionais do barril do petróleo para menos de US\$50,00 ao final de 2014, interrompendo trajetória de boom cujo pico de US\$145.00 ocorreu em 2008, houve forte queda na arrecadação estadual e dos municípios receptores das rendas do petróleo. Com isso, os governos endividaram-se antecipando receitas do petróleo. No caso do governo estadual, essa antecipação, que ocorre desde 2013, esteve associada à ampla concessão de incentivos fiscais, engendrando grave crise fiscal que culminou com o decreto de calamidade pública em 2016. Vianna da Cruz (2016) afirma que o grande volume de arrecadação dessas receitas nos anos anteriores, com base em recursos naturais não renováveis, refletiu-se em certa inércia dos gestores públicos nos municípios do Norte Fluminense no que se refere a ações de diversificação produtiva, melhorias da arrecadação e resolução de problemas sociais decorrentes da pressão dessas atividades sobre a infraestrutura urbana.

Além disso, quando se observam os grandes projetos de investimento no ERJ (arco rodoviário metropolitano, indústria naval, petroquímica, siderurgia, com grande concentração na RMRJ; e infraestrutura portuária e mineroduto ao longo do litoral fluminense: Porto do Açu, em São João da Barra/Norte Fluminense, e Porto de Sepetiba, em Itaguaí na RMRJ), constata-se grande articulação com a tendência extrativista exportadora e de "reterritorialização" nacional. Segundo Vianna da Cruz (2013), são projetos que não estão orientados para a integração intrarregional, mas para o exterior, sendo vetores de fragmentação territorial e social em um contexto regional e urbano já marcado por fortes heranças de desigualdades econômicas e socioespaciais.

No que concerne à RMRJ, que concentra cerca de $70 \%$ da população e $60 \%$ do PIB fluminenses, não há robustez da dinâmica industrial, embora estejam aí localizadas atividades da indústria naval em Niterói, a refinaria e o polo gás-químico em Duque de Caxias, a indústria siderúrgica no distrito de Santa Cruz e em Itaguaí e o grande projeto de investimento petroquímico, Comperj, nos municípios de Itaboraí e São Gonçalo. Há também forte concentração no município do Rio de Janeiro que responde por cerca de $40 \%$ do PIB fluminense.

Cabe destacar que essa é uma característica histórica da RMRJ em que a indústria de transformação não alcançou centralidade na estruturação do espaço urbano e regional. De acordo com Ribeiro (1997), a explicação para isso está relacionada à hegemonia política de grupos sociais dos setores da construção civil, incorporadores imobiliários, proprietários de terra e concessionários de serviços urbanos. Dessa forma, o papel dos serviços na economia metropolitana, considerando a problemática do desenvolvimento produtivo pouco integrado, tem seu caráter dinâmico restrito. Em termos intrametropolitanos, a ausência de outras centralidades em comparação ao município-polo reflete-se em intensa mobilidade urbana em que se articulam graves problemas do sistema de transporte, de desigualdade social e de segregação socioespacial. 
Diante de tais características, as questões do trabalho no contexto urbano-regional fluminense se articulam às de um espaço econômico urbano dominado pelas atividades de serviços, altamente concentradas em sua área metropolitana, especialmente no município do Rio de Janeiro. Ao mesmo tempo, são significativas as problemáticas do emprego correspondente a uma estrutura produtiva altamente especializada em setores intensivos em recursos naturais não renováveis para exportação e capital-intensivos. Portanto, conformando dinâmicas de emprego altamente vulneráveis às flutuações cíclicas de preços e da demanda externa.
Os dados da Pnad do IBGE, no Gráfico 1, demonstram que, acompanhando a trajetória nacional, houve um contínuo crescimento do percentual da população ocupada no total da população economicamente ativa entre 20032012, com tendência de queda a partir de 2013 na RMRJ. Nas demais regiões do ERJ (ERJ sem RMRJ), ${ }^{10}$ o crescimento desse percentual ocorreu a partir de 2005. Provavelmente sob influência dos efeitos da redução do boom de preços do petróleo nessa região, ocorreu uma queda do percentual de ocupados entre 20082009, com pequena recuperação entre 2011 2013, voltando a cair em 2014.

Gráfico 1 - Percentual de pessoas ocupadas no total da população economicamente ativa, RMRJ e ERJ sem RMRJ, 2003-2014

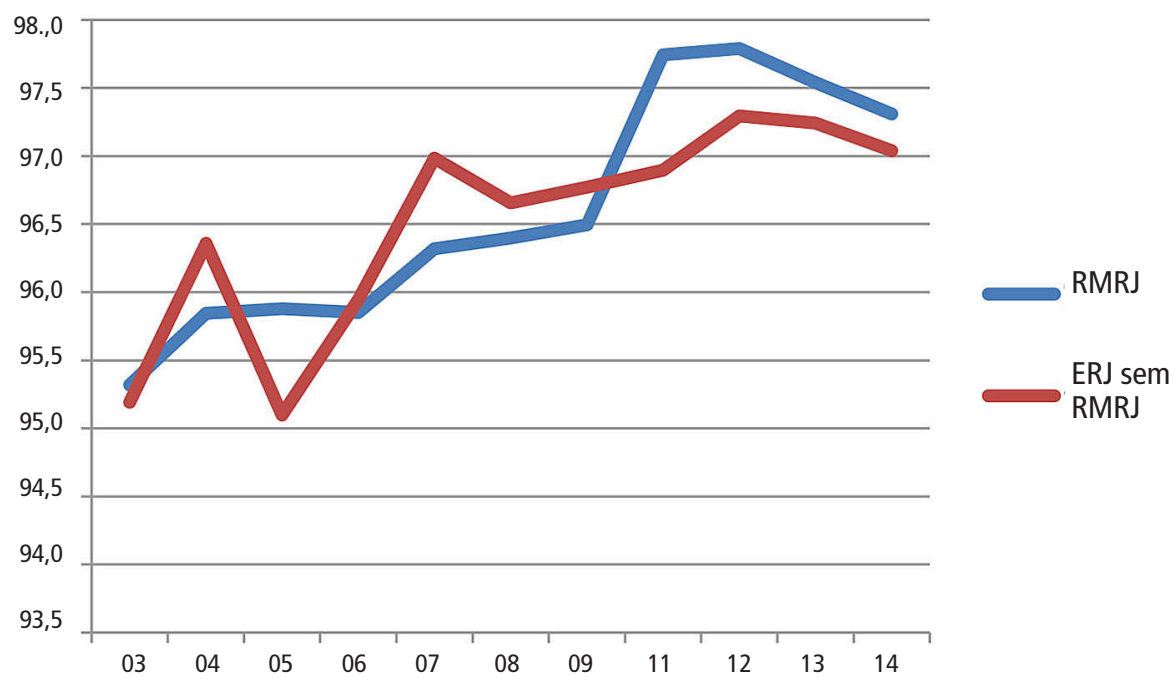

Fonte: IBGE, Pnad - Pesquisa Nacional por Amostra de Domicílios. Pessoas de 10 anos ou mais de idade. 
No que se refere ao perfil dos ocupados, pelos dados da Tabela 1, outras tendências positivas são observadas pelo crescimento contínuo do percentual daqueles empregados com carteira de trabalho na RMRJ e no ERJ sem RMRJ. Também houve redução do percentual de trabalho doméstico, porém, sem redução significativa das ocupações sem carteira de trabalho. No caso dos ocupados por conta própria, houve ligeira queda entre 2011-2012, voltando a subir em 2013-2014 em ambas as regiões. De modo geral, na RMRJ, no período após a eclosão da crise internacional, não se observa, até 2014, deterioração dos vínculos empregatícios. A situação é um pouco distinta no ERJ sem RMRJ, com tendência de redução relativa dos empregados com carteira e ocupados por conta própria a partir de 2013.

Tabela 1 - Percentual dos ocupados, por posição na ocupação no trabalho principal, RMRJ e ERJ sem RMRJ, 2003-2014

\begin{tabular}{|c|c|c|c|c|c|c|c|c|}
\hline & Posição na ocupação & 3 & 8 & 9 & 11 & 12 & 13 & 14 \\
\hline \multirow{11}{*}{ RMRJ } & Empregado & 37,0 & 37,3 & 37,4 & 37,9 & 38,3 & 38,5 & 38,3 \\
\hline & Empregado - com CTPS & 23,0 & 23,9 & 24,8 & 26,9 & 26,4 & 27,1 & 27,4 \\
\hline & Empregado militar e funcionário público estatutário & 5,7 & 5,1 & 4,9 & 4,9 & 5,2 & 5,2 & 5,1 \\
\hline & Empregado - outro & 8,3 & 8,4 & 7,7 & 6,1 & 6,7 & 6,3 & 5,8 \\
\hline & Trabalhador doméstico & 5,4 & 4,9 & 5,2 & 5,0 & 5,2 & 4,6 & 4,8 \\
\hline & Trabalhador doméstico - com CTPS & 1,8 & 1,6 & 1,7 & 1,8 & 2,0 & 1,8 & 1,6 \\
\hline & Trabalhador doméstico - sem CTPS & 3,6 & 3,3 & 3,5 & 3,2 & 3,2 & 2,8 & 3,2 \\
\hline & Empregador & 2,2 & 2,2 & 2,3 & 1,8 & 1,5 & 1,8 & 1,7 \\
\hline & Conta própria & 12,6 & 12,7 & 12,0 & 12,2 & 11,3 & 11,7 & 11,8 \\
\hline & Não remunerado & 0,5 & 0,6 & 0,5 & 0,3 & 0,2 & 0,2 & 0,3 \\
\hline & Total & 100 & 100 & 100 & 100 & 100 & 100 & 100 \\
\hline \multirow{11}{*}{$\begin{array}{l}\text { ERJ } \\
\text { sem } \\
\text { RMRJ }\end{array}$} & Empregado & 34,5 & 37,6 & 37,0 & 36,8 & 37,4 & 37,4 & 36,2 \\
\hline & Empregado - com CTPS & 19,9 & 22,5 & 22,9 & 23,3 & 24,2 & 23,5 & 24,0 \\
\hline & Empregado militar e funcionário público estatutário & 4,7 & 5,1 & 5,7 & 5,5 & 5,7 & 5,4 & 4,9 \\
\hline & Empregado - outro & 9,8 & 9,8 & 8,4 & 8,0 & 7,6 & 8,5 & 7,4 \\
\hline & Trabalhador doméstico & 7,3 & 5,5 & 6,2 & 6,5 & 5,9 & 5,5 & 5,7 \\
\hline & Trabalhador doméstico - com CTPS & 2,2 & 2,0 & 2,3 & 2,3 & 2,2 & 2,3 & 2,3 \\
\hline & Trabalhador doméstico - sem CTPS & 5,1 & 3,5 & 3,9 & 4,2 & 3,7 & 3,3 & 3,4 \\
\hline & Empregador & 2,3 & 2,2 & 2,4 & 1,6 & 2,3 & 2,3 & 2,8 \\
\hline & Conta própria & 13,4 & 10,8 & 10,3 & 11,3 & 10,8 & 11,5 & 12,8 \\
\hline & Não remunerado & 0,8 & 0,9 & 1,0 & 0,6 & 0,2 & 0,3 & 0,6 \\
\hline & Total & 100 & 100 & 100 & 100 & 100 & 100 & 100 \\
\hline
\end{tabular}

Fonte: IBGE, Pnad - Pesquisa Nacional por Amostra de Domicílios. Pessoas de 10 anos ou mais de idade. 
Em termos do perfil setorial dos ocupados, observa-se na Tabela 2 que os grupos de atividades no setor de serviços têm maior importância no total de ocupados da RMRJ. Os maiores percentuais são de ocupações em comércio e reparação; outras atividades; educação, saúde e serviços pessoais; e construção. Entre 2009-2014, perderam participação relativa as ocupações nos setores industrial; transporte, armazenagem e comunicação; serviços domésticos; e outros serviços coletivos, sociais e pessoais. Nesse mesmo período, houve aumento das ocupações no setor de construção; de alojamento e alimentação, corroborando com os projetos econômicos mais recentes na região; e de administração pública.

No ERJ sem RMRJ, o maior percentual de ocupações também está nos grupos de atividades de serviços, contrastando com uma queda importante nos percentuais relativos das atividades agrícolas e da indústria de transformação que ocorre desde 2003 (Tabela 3). Além desses, entre 2009-2014, também reduziram seu peso relativo as ocupações em administração pública; serviços domésticos; e outras atividades. Nesse mesmo período, aumentaram os pesos relativos de construção; comércio e reparação; alojamento e alimentação; e outros serviços coletivos, sociais e pessoais.

Tabela 2 - Percentual dos ocupados, por grupamento de atividade do trabalho principal, RMRJ e ERJ sem RMRJ, 2003, 2009 e 2014

\begin{tabular}{l|r|r|r}
\hline \multicolumn{1}{c|}{ Grupamento de atividade } & 2003 & 2009 & 2014 \\
\hline Agrícola & 0,6 & 0,4 & 0,3 \\
Indústria & 10,2 & 10,5 & 8,0 \\
Indústria de transformação & 9,5 & 9,5 & 7,1 \\
Construção & 7,0 & 6,8 & 9,1 \\
Comércio e reparação & 18,6 & 17,2 & 18,1 \\
Alojamento e alimentação & 4,9 & 5,4 & 6,3 \\
Transporte, armazenagem e comunicação & 6,9 & 7,6 & 7,3 \\
Administração pública & 6,2 & 5,2 & 6,1 \\
Educação, saúde e serviços sociais & 10,9 & 10,6 & 10,8 \\
Serviços domésticos & 8,5 & 8,5 & 7,9 \\
Outros serviços coletivos, sociais e pessoais & 5,1 & 6,7 & 5,7 \\
Outras atividades & 11,6 & 11,5 & 13,3 \\
\hline Total & 100 & 100 & 100 \\
\hline
\end{tabular}

Fonte: IBGE, Pnad - Pesquisa Nacional por Amostra de Domicílios. Pessoas de 10 anos ou mais de idade. 
Tabela 3 - Percentual dos ocupados, por grupamento de atividade do trabalho principal, ERJ sem RMRJ, 2003, 2009 e 2014

\begin{tabular}{l|r|r|r}
\hline \multicolumn{1}{c|}{ Grupamento de atividade } & 2003 & 2009 & 2014 \\
\hline Agrícola & 6,2 & 4,3 & 3,9 \\
Indústria & 13,9 & 14,1 & 12,3 \\
Indústria de transformação & 12,3 & 11,9 & 9,5 \\
Construção & 9,6 & 9,1 & 12,0 \\
Comércio e reparação & 15,9 & 15,2 & 17,3 \\
Alojamento e alimentação & 4,2 & 4,2 & 5,8 \\
Transporte, armazenagem e comunicação & 3,8 & 4,3 & 4,5 \\
Administração pública & 5,0 & 6,1 & 5,9 \\
Educação, saúde e serviços sociais & 8,6 & 10,4 & 10,1 \\
Serviços domésticos & 10,9 & 10,4 & 8,8 \\
Outros serviços coletivos, sociais e pessoais & 3,7 & 3,5 & 4,0 \\
Outras atividades & 5,8 & 6,5 & 5,9 \\
\hline Total & 100 & 100 & 100 \\
\hline
\end{tabular}

Fonte: IBGE, Pnad - Pesquisa Nacional por Amostra de Domicílios. Pessoas de 10 anos ou mais de idade.

Pelos dados da Pnad Contínua trimestral, disponíveis apenas para o ERJ, é possível verificar os efeitos da conjuntura sobre as ocupações (Gráfico 2). Em ambiente de crise nacional e estadual, há uma piora do quadro geral dos vínculos, com redução do peso relativo do emprego no setor privado (exclusive o doméstico) e aumento da participação da ocupação por conta própria até o trimestre de abril-junho de 2016. Também ocorre ligeira elevação do peso relativo do emprego doméstico sem carteira.

A partir de 2015, os dados da PME do IBGE, disponíveis apenas para a RMRJ, mostram que há aumento do total de desocupados (Gráfico 3). A desocupação atingiu maiores níveis entre os meses de setembro e novembro de 2015, com redução a partir de dezembro de 2015 até fevereiro de 2016. Porém, demonstrando em janeiro e fevereiro de 2016 um aumento significativo em relação aos meses de janeiro e fevereiro de 2015.

A revisão do plano de negócios da Petrobras afetou negativamente setores estratégicos para a diversificação industrial, como é o caso do setor naval. Houve demissões em estaleiros da Sete Brasil em Niterói, Brasfels em Angra dos Reis e encerramento das atividades do estaleiro Ilha SA na cidade do Rio. Em Niterói, a empresa Eisa-Petro Um interrompeu suas operações e a Transpetro cancelou encomendas de navios petroleiros. Efeitos negativos ocorrem com a paralisação de obras de grandes projetos, tais como o do Comperj. 


\section{Gráfico 2 - Percentual de ocupados, por posição na ocupação} no trabalho principal, ERJ, trimestres de 2015 a 2016

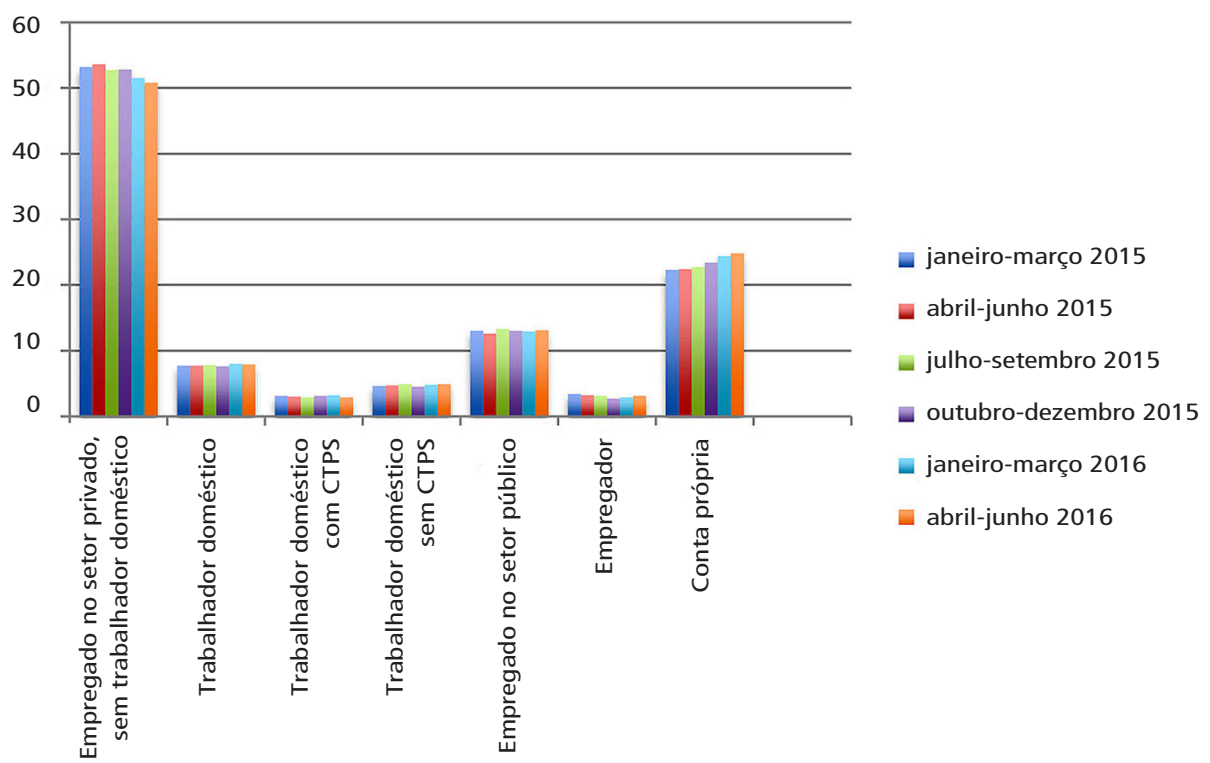

Fonte: IBGE - Pesquisa Nacional por Amostra de Domicílios Contínua trimestral. Pessoas de 14 anos ou mais de idade.

Gráfico 3 - Total de pessoas desocupadas, RMRJ, janeiro de 2015 a janeiro de 2016

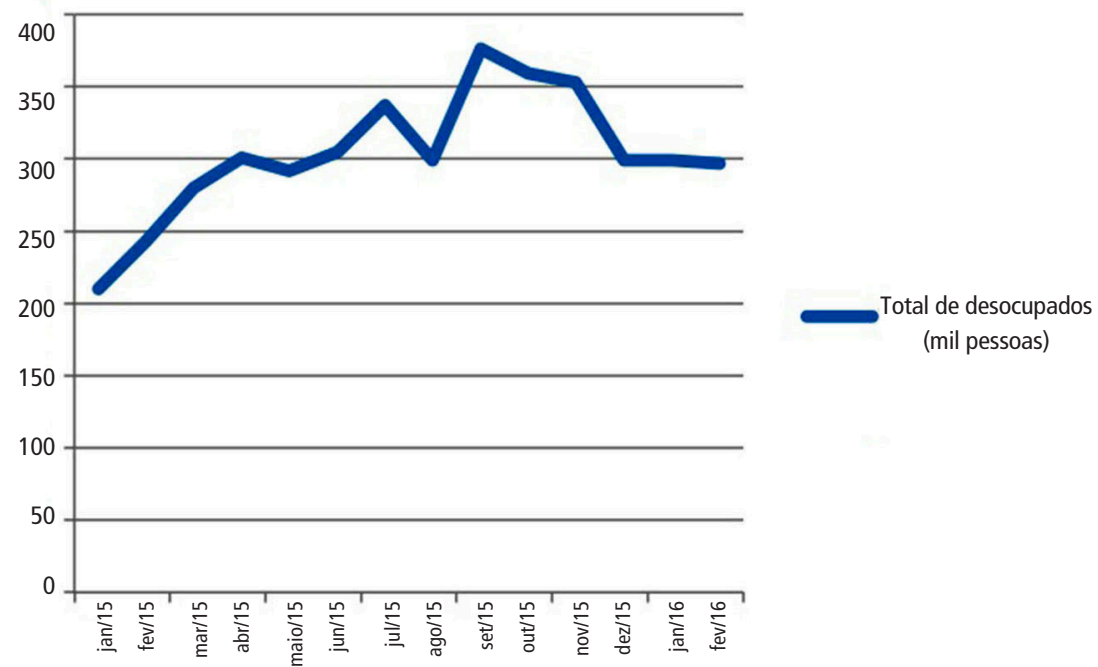

Fonte: IBGE - Pesquisa Mensal de Emprego.

Pessoas de 10 anos ou mais de idade, desocupadas na semana de referência. 
Por outro lado, é importante ressaltar que as mudanças gerais no mercado de trabaIho, apesar dos indicadores positivos até 2014, ocorreram num quadro geral de flexibilização e terceirização das relações de trabalho, instaurado desde os anos 1990, tal como demonstram as pesquisas setoriais específicas.

A implantação de grandes projetos de investimento no ERJ (Comperj, Porto de Sepetiba e Porto do Açu) e das várias obras para os megaeventos, bem como construções de edifícios residenciais, é articulada entre vários consórcios empresariais, compreendendo cadeias complexas de subcontratação. De modo geral, refletindo-se em tendências de fragmentação das ocupações no âmbito do mercado interno de trabalho, bem como no âmbito espacial (entre o município de trabalho e a moradia).

Além disso, os estudos apresentados em livro organizado por Ramalho e Fortes (2012) demonstram a articulação de questões ambientais e laborais no ERJ, uma vez que muitos são empreendimentos instalados em áreas de grande vulnerabilidade, envolvendo elevados riscos de acidentes de trabalho e ambientais. ${ }^{11}$ Também se destaca, no polo automobilístico do Sul Fluminense, a organização de um mercado de trabalho sob novas formas de organização produtiva, como o Consórcio Modular $^{12}$ introduzido pela Volkswagen na fabricação de caminhões em Resende. Com isso, complexificando o quadro de segmentação das relações de trabalho no interior de uma mesma planta industrial.

Há distintas situações, por exemplo: as atividades do setor de petróleo e química na região metropolitana se desenvolvem em contextos precários de infraestrutura urbana, de baixa renda, escolarização e qualificação da mão de obra. Ao mesmo tempo, atraem mão de obra de outros locais, não apenas de postos mais qualificados, mas também para as obras de construção. A extração de petróleo e gás no Norte Fluminense atraiu grande contingente populacional exercendo pressões sobre a infraestrutura urbana. Com as obras do Comperj (Itaboraí e São Gonçalo na RMRJ), foram atraídos trabalhadores da construção civil, e as perspectivas de desenvolvimento econômico pressionaram fortemente os preços imobiliários em cidades com grande população em situações precárias de emprego, renda e moradia. Também há informações sobre conflitos socioambientais em torno de projetos, tais como a construção de uma barragem no Rio Guapiaçu pelo Comperj e seus impactos para várias famílias de agricultores.

\section{Considerações finais}

Este artigo discutiu a importância das transformações espaciais e do trabalho para a compreensão das características, contradições e crise do processo de desenvolvimento em âmbito nacional. A partir do exame das interpretações e de dados estatísticos, foram observadas tendências positivas, mas também contraditórias ao longo do período 2003-2014, que acabaram por culminar com a crise econômica e política brasileira a partir de 2015. 0 estado do Rio de Janeiro, tendo em vista sua forte articulação com tais tendências, pode ser visto como espaço privilegiado para a análise desses movimentos. 
Através da análise empreendida por este artigo, foi possível demonstrar como especialização e reprimarização da base produtiva articularam-se a uma dinâmica fortemente cíclica da economia e do mercado de trabalho fluminense. Grandes projetos de investimento em infraestrutura portuária e logística e de megaeventos internacionais também denotam forte internacionalização da economia fluminense. São projetos que privilegiam a integração ao mercado internacional em detrimento de uma integração intrarregional e intrametropolitana voltada para a redução de desigualdades econômicas e socioespaciais.

À luz de suas questões históricas, as questões do trabalho no contexto fluminense articulam-se às de um espaço econômico urbano dominado pelas atividades de serviços, altamente concentradas em sua área metropolitana, sobretudo no município-polo. Ao mesmo tempo, são significativas as problemáticas do emprego em uma estrutura produtiva altamente especializada em recursos naturais não renováveis, conformando dinâmicas altamente vulneráveis às flutuações cíclicas de preços e da demanda externa.

0 quadro instaurado a partir de 2015, de crise econômica e política, ao mesmo tempo que revela mais claramente os limites e as contradições do modelo econômico e político brasileiro, é extremamente preocupante. Ainda não estão muito definidas as mudanças vindouras, mas as propostas políticas que têm sido divulgadas indicam uma nova rodada neoliberal, com sérias implicações sobre as dimensões espaciais e do "mundo do trabalho" no Brasil e no estado do Rio de Janeiro.

\section{Hipólita Siqueira de Oliveira}

Universidade Federal do Rio de Janeiro, Instituto de Pesquisa e Planejamento Urbano e Regional. Rio de Janeiro, RJ/Brasil.

hipolitaufrj@gmail.com

\section{Notas}

(*) A autora agradece aos comentários dos pareceristas anônimos e aos auxílios de pesquisa do CNPq e da Faperj.

(1) Dados das Contas Nacionais do IBGE.

(2) Dados das Contas Nacionais do IBGE.

(3) A série teve seu início no primeiro trimestre de 2012. 
(4) A complexidade desse processo pode ser observada sob distintas formas (em geral visto pela redução da participação do setor industrial no PIB e no emprego nacional) e abordagens analíticas sobre as manifestações e especificidades da desindustrialização no Brasil (precoce e relativa).

(5) São exemplos, a instalação da Companhia Siderúrgica Nacional/CSN, em 1941 (Volta Redonda); da Companhia Vale do Rio Doce/CVRD, em 1942; Fábrica Nacional de Motores, em 1948 (Magé); Petrobras em 1953; Frota Nacional de Petroleiros/Fronape, em 1954; Furnas Centrais Elétricas, em 1957; Refinaria Duque de Caxias/ Reduc (Duque de Caxias) e Eletrobrás, em 1961; Companhia de Pesquisa de Recursos Minerais/CPRM, em 1969; além de investimentos em infraestrutura rodoviária já nos anos 1950 (BR 116 e BR 101).

(6) Várias multinacionais do setor instalaram-se no Norte Fluminense e na cidade do Rio, por exemplo, Baker Hughes, FMC Technologies, Halliburton, Vallourec, General Electric, dentre outras.

(7) Em 29 de julho de 2016, a Petrobras anunciou a venda por US\$2,5 bilhões, de 66\% de participação no bloco exploratório de Carcará, no pré-sal da Bacia de Santos (que se estende de Cabo Frio/RJ a Florianópolis/SC), para a estatal norueguesa Statoil.

(8) Santos, Marafon e Sant'Anna (2012); Silva (2012) e Ribeiro (2015).

(9) Dados da ANP (Agência Nacional do Petróleo, Gás Natural e Biocombustíveis).

(10) A Pnad disponibiliza apenas os dados agregados para o estado do Rio de Janeiro e Região Metropolitana do Rio de Janeiro. Sendo assim, para se ter uma visão geral sobre o emprego fora da RMRJ, optou-se por excluir do ERJ os dados metropolitanos.

(11) Tal como no caso das explosões da plataforma P-36 da Petrobras em 2001, causando a morte de 11 trabalhadores. Outros exemplos são as atividades da siderúrgica TKCSA em Itaguaí, cuja instalação envolveu projetos de aterramento e dragagem de alto impacto ambiental.

(12) O Consórcio Modular consiste na integração, dentro de uma mesma planta, de fornecedores na montagem de um conjunto completo de partes automotivas, ficando a empresa automobilística responsável por atividades como projeto, desenvolvimento, certificação, etc.

\section{Referências}

ARAUJO, T. B. (2013). "Tendências do desenvolvimento regional recente no Brasil". In: BRANDÃO, C. A. e SIQUEIRA, H. (orgs.). Pacto federativo, Integração Nacional e Desenvolvimento Regional. São Paulo, Fundação Perseu Abramo.

BARTELT, D. (ed.). (2013). A "Nova Classe Média" no Brasil como conceito e projeto político. Rio de Janeiro, Fundação Heinrich Böll.

BRAGA, R. (2012). A política do precariado: do populismo à hegemonia lulista. São Paulo, Boitempo.

BRESSER-PEREIRA, L. C. (org.) (2013). O que esperar do Brasil? Rio de Janeiro, Editora da FGV. 
CARDOSO, A. L. e ARAGÃO, T. A. (2013). “Do fim do BNH ao Programa Minha Casa Minha Vida: 25 anos da política habitacional no Brasil”. In: CARDOSO, A. L. (org.). O Programa Minha Casa Minha e seus efeitos territoriais. Rio de Janeiro, Letra Capital.

CARNEIRO, R. (2012a). Commodities, choques externos e crescimento: reflexões sobre a América Latina. CEPAL-Serie Macroeconomía del desarrollo. Santiago, n. 117, pp. 1-47.

(2012b). Velhos e novos desenvolvimentismos. Economia e Sociedade. Campinas, v. 21, número especial, pp. 749-778.

CASTRO, D. G. et al. (orgs.) (2015). Rio de Janeiro: os impactos da Copa do Mundo e das Olimpíadas 2016. Rio de Janeiro, Letra Capital.

DIEESE (2016). Impactos da recessão econômica e do ajuste fiscal sobre o mercado de trabalho no Brasil. Nota Técnica DIEESE, n. 159.

FONSECA, P. C. D. et al. (2013). O Brasil na era Lula: retorno ao desenvolvimentismo? Nova Economia. Belo Horizonte, v. 23, n. 2, pp. 403-428.

GONÇALVES, R. (2013). Desenvolvimento às avessas. Rio de Janeiro, LTC.

KREIN, J. D.; DIAS, H. R. e COLOMBI, A. P. F. (2015). As centrais sindicais e a dinâmica do emprego. Estudos Avançados. São Paulo, v. 29, n. 85, pp. 121-135.

LESSA, C. (2000). O Rio de todos os Brasis: uma reflexão em busca de autoestima. Rio de Janeiro, Record.

NERI, M. (2011). A nova classe média: o lado brilhante da base da pirâmide. São Paulo, Saraiva.

NOBRE, M. (2013). Imobilismo em movimento. São Paulo, Companhia das Letras.

OLIVEIRA, F.; RIZEK, C. e BRAGA, R. (2010). Hegemonia às avessas: economia, política e cultura na era da servidão financeira. São Paulo, Boitempo.

PAULANI, L. (2013). Acumulação sistêmica, poupança externa e rentismo: observações sobre o caso brasileiro. Estudos Avançados. São Paulo, v. 27 n. 77 pp. 237-261.

PEREIRA, L. V. (2012). “As exportações fluminenses: a maldição dos recursos naturais?”. In: PINHEIRO, A. C. e VELOSO, F. (orgs.). Rio de Janeiro: um estado em transição. Rio de Janeiro, Editora da FGV.

PINTO, E. C. (2010). Bloco no poder e governo Lula. Tese de doutoramento. Rio de Janeiro, Universidade Federal do Rio de Janeiro.

PIQUET, R. (1993). Reestruturação do espaço regional e urbano no Brasil: o poder do Estado e dos grandes investimentos. Rio de Janeiro, Ippur-UFRJ.

POCHMANN, M. (2012). Nova classe média? São Paulo, Boitempo.

RAMALHO, J. R. e FORTES, A. (orgs.) (2012). Desenvolvimento, trabalho e cidadania. Baixada e Sul Fluminense. Rio de Janeiro, 7 Letras.

RIBEIRO, L. C. Q. (1997). Segregação, acumulação urbana e poder na Metrópole do Rio de Janeiro. Cadernos IPPUR. Rio de Janeiro, n. 19, pp. 1-21.

(2015). A metrópole do Rio de Janeiro na transição da ordem urbana brasileira: 1970/2010. Rio de Janeiro, Letra Capital.

SANTOS, A. M. S. P.; MARAFON, G. J. e SANT`ANNA, M. J. G. (orgs.) (2012). Rio de Janeiro: um território em mutação. Rio de Janeiro, Gramma/Faperj. 
SILVA, R. D. (2012). Indústria e desenvolvimento regional no Rio de Janeiro (1990-2008). Rio de Janeiro, Editora da FGV.

SINGER, A. (2012). Os sentidos do Lulismo. São Paulo, Companhia das Letras.

VIANNA DA CRUZ, J. L. (2013). Os desafios da construção do desenvolvimento no Estado do Rio de Janeiro. Cadernos do Desenvolvimento Fluminense. Rio de Janeiro, n. 2, pp. 51-86.

(2016). Crise do petróleo, dependência dos royalties e ajuste fiscal: o caso do Município de Campos dos Goytacazes/RJ. Boletim Petróleo, Royalties e Região. Campos dos Goytacazes, Ano XIII, n. 51.

Texto recebido em 30/set/2016

Texto aprovado em 30/nov/2016 